Louisiana State University

LSU Digital Commons

6-23-2015

\title{
Structural Analysis of Substrate, Reaction Intermediate, and Product Binding in Haemophilus influenzae Biotin Carboxylase
}

Tyler C. Broussard

Louisiana State University

Svetlana Pakhomova

Louisiana State University

David B. Neau

Cornell University

Ross Bonnot

Louisiana State University

Grover L. Waldrop

Louisiana State University

Follow this and additional works at: https://digitalcommons.Isu.edu/biosci_pubs

\section{Recommended Citation}

Broussard, T., Pakhomova, S., Neau, D., Bonnot, R., \& Waldrop, G. (2015). Structural Analysis of Substrate, Reaction Intermediate, and Product Binding in Haemophilus influenzae Biotin Carboxylase. Biochemistry, 54 (24), 3860-3870. https://doi.org/10.1021/acs.biochem.5b00340

This Article is brought to you for free and open access by the Department of Biological Sciences at LSU Digital Commons. It has been accepted for inclusion in Faculty Publications by an authorized administrator of LSU Digital Commons. For more information, please contact ir@lsu.edu. 


\title{
Structural Analysis of Substrate, Reaction Intermediate, and Product Binding in Haemophilus influenzae Biotin Carboxylase
}

\author{
Tyler C. Broussard ${ }^{\dagger}$, Svetlana Pakhomova ${ }^{\dagger}$, David B. Neau ${ }^{\ddagger}$, Ross Bonnot $^{\dagger}$, and Grover L. \\ Waldrop ${ }^{*} \dagger$ \\ †Department of Biological Sciences, Louisiana State University, Baton Rouge, Louisiana 70803, \\ United States \\ ‡Department of Chemistry and Chemical Biology, Cornell University, Northeastern Collaborative \\ Access Team, Argonne National Laboratory, Argonne, Illinois 60439, United States
}

\section{Abstract}

Acetyl-CoA carboxylase catalyzes the first and regulated step in fatty acid synthesis. In most Gram-negative and Gram-positive bacteria, the enzyme is composed of three proteins: biotin carboxylase, a biotin carboxyl carrier protein (BCCP), and carboxyltransferase. The reaction mechanism involves two half-reactions with biotin carboxylase catalyzing the ATP-dependent carboxylation of biotin-BCCP in the first reaction. In the second reaction, carboxyltransferase catalyzes the transfer of the carboxyl group from biotin-BCCP to acetyl-CoA to form malonylCoA. In this report, high-resolution crystal structures of biotin carboxylase from Haemophilus influenzae were determined with bicarbonate, the ATP analogue AMPPCP; the carboxyphosphate intermediate analogues, phosphonoacetamide and phosphonoformate; the products ADP and phosphate; and the carboxybiotin analogue $\mathrm{N1}$ '-methoxycarbonyl biotin methyl ester. The structures have a common theme in that bicarbonate, phosphate, and the methyl ester of the carboxyl group of $\mathrm{N1}^{\prime}$-methoxycarbonyl biotin methyl ester all bound in the same pocket in the active site of biotin carboxylase and as such utilize the same set of amino acids for binding. This finding suggests a catalytic mechanism for biotin carboxylase in which the binding pocket that binds tetrahedral phosphate also accommodates and stabilizes a tetrahedral dianionic transition state resulting from direct transfer of $\mathrm{CO}_{2}$ from the carboxyphosphate intermediate to biotin.

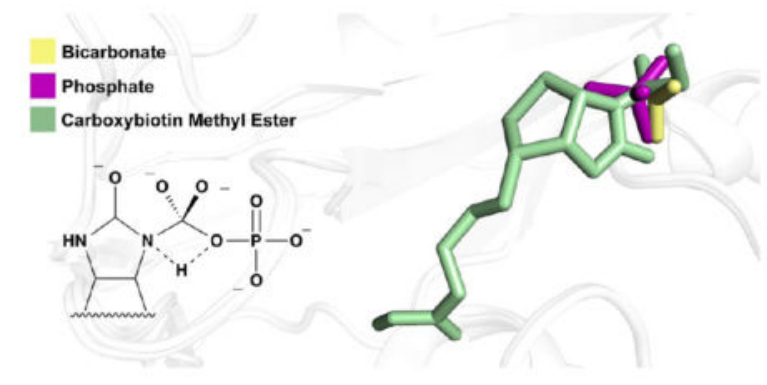

\footnotetext{
*Corresponding Author: Department of Biological Sciences, Room 206, Life Sciences Building, Louisiana State University, Baton Rouge, LA 70803. gwaldro@1su.edu. Telephone: (225) 578-5209.

Notes

The authors declare no competing financial interest.
} 
The vitamin biotin is a cofactor for enzymes involved in the metabolism of $\mathrm{CO}_{2} .{ }^{1}$ For the biotin-dependent carboxylases, bicarbonate is utilized as the source of $\mathrm{CO}_{2}$. Biotindependent carboxylases are multifunctional enzymes in that they are composed of three different proteins: biotin carboxylase, a biotin carboxyl carrier protein (BCCP) that is covalently linked to biotin, and a carboxyltransferase. In eukaryotes, all three proteins form different domains on a single polypeptide chain, ${ }^{2}$ while in prokaryotes, the functional enzymatic unit consists of a complex of all three proteins. ${ }^{3}$ This multifunctional character means biotin-dependent carboxylations occur via two half-reactions shown in Scheme 1.

In the first half-reaction, catalyzed by biotin carboxylase, ATP is used to activate bicarbonate by forming a carboxyphosphate intermediate (Figure 1A). The carboxyl group is transferred to biotin (designated as E-biotin in Scheme 1 to indicate that it is attached to BCCP) by direct attack on carboxyphosphate, ${ }^{4}$ or carboxyphosphate decomposes in the active site to form phosphate and the more electrophilic $\mathrm{CO}_{2} \cdot{ }^{4,5}$ The reaction catalyzed by biotin carboxylase also requires two metal ions; one is bound to ATP such that the metalnucleotide chelate is the substrate, and the other metal ion binds in the active site. ${ }^{6}$ While the first half-reaction is virtually identical in all biotin-dependent carboxylases, the second halfreaction, catalyzed by carboxyltransferase, varies depending on the specific acceptor molecule. For example, acetyl-CoA is the acceptor for acetyl-CoA carboxylase.

The three-dimensional structure of the Escherichia coli biotin carboxylase subunit from acetyl-CoA carboxylase revealed that the enzyme belongs to the ATP-grasp superfamily of enzymes. ${ }^{7,8}$ Members of this superfamily of enzymes catalyze the reaction of a carboxyl group with either a nitrogen or a sulfur nucleophile. ${ }^{9}$ The carboxyl group is activated for nucleophilic attack by reacting with ATP to form an acyl phosphate intermediate. Biotin carboxylase and all members of the ATP-grasp superfamily of enzymes contain three structural domains (Figure 2A). ${ }^{7}$ The N-terminus or A-domain is formed by a five-stranded parallel $\beta$-sheet flanked on either side by a total of four $\alpha$-helices. The $\mathrm{N}$-terminal domain is connected to the central or B-domain, which is composed of a three-stranded antiparallel $\beta$ sheet covered on one side by two $\alpha$-helices with the second and third $\beta$-strands of the Bdomain connected by a highly flexible glycine rich loop called the T-loop. The C-domain contains an eight-stranded antiparallel $\beta$-sheet, a three-stranded antiparallel $\beta$-sheet, and seven $\alpha$-helices.

Since the original structure of biotin carboxylase was published, ${ }^{10}$ there have been numerous structures of the enzyme from several different bacteria that have either ATP, ${ }^{11}$ $\mathrm{ADP},{ }^{12}$ or nucleotide analogues such as AMPPNP bound in the active site. ${ }^{12}$ One structure of biotin carboxylase contained the product ADP along with the substrates bicarbonate and biotin. ${ }^{13}$ The current structures show that the A- and C-domains form a platform for substrate binding and that upon nucleotide binding the B-domain rotates $\sim 45^{\circ}$ relative to the A-and C-domains to cover the active site (Figure 2B). Moreover, the T-loop that is disordered in the absence of ATP becomes ordered upon nucleotide binding because the main chain amides of the glycine residues hydrogen bond to the $\beta$ - and $\gamma$-phosphoryl oxygens of ATP. While these structures have been invaluable for understanding the function of biotin carboxylase, they provide an incomplete picture of the mechanism of biotin carboxylase. Missing are three-dimensional structures that show the relative positions of the 
substrates and products of the reaction. The high-resolution crystal structures described in this report fill this void, provide insight into the chemical mechanism of biotin-dependent carboxylations, and suggest a mechanism for how the biotin-dependent carboxylases evolved to bind bicarbonate.

\section{EXPERIMENTAL PROCEDURES}

\section{Reagents}

Crystallization reagents, 24-well sitting drop trays, 0.1-0.2 mm mounted cryoloops, and CrystalCap Magnetic caps were purchased from Hampton Research. Phosphonoacetamide was a gift from H. K. Schachman of the University of California (Berkeley, CA). All other reagents were from Sigma-Aldrich.

\section{Crystallization of Biotin Carboxylase}

Biotin carboxylase from Haemophilus inf luenzae was a gift from Pfizer. The sequence of the protein can be found at the National Center for Biotechnology Information Web site under the protein database as accession number P43873.1. Biotin carboxylase was cocrystallized with each of the following ligands: $\mathrm{ADP}+\mathrm{PO}_{4}, \mathrm{HCO}_{3}{ }^{-}+\mathrm{AMPPCP}$, AMPPCP $+\mathrm{Mg}^{2+}$, phosphonoacetamide (PAM), phosphonoformate (POF), AMPPCP + $\mathrm{PO}_{4}, \mathrm{HCO}_{3}{ }^{-}$, and $\mathrm{ADP}+\mathrm{N1}^{\prime}$-methoxycarbonyl biotin methyl ester. For all of the ligands, except $\mathrm{N1}^{\prime}$-methoxycarbonyl biotin methyl ester, a small volume of ligand solution was mixed with a $10.6 \mathrm{mg} / \mathrm{mL}$ solution of biotin carboxylase dissolved in $10 \mathrm{mM}$ HEPES (pH 7.2), $150 \mathrm{mM} \mathrm{KCl}$, and $1 \mathrm{mM}$ TCEP [tris(2-carboxyethyl)phosphine]. Because N1'methoxycarbonyl biotin methyl ester was water insoluble, the compound was added as a solid to a solution of protein and incubated at $4{ }^{\circ} \mathrm{C}$ for 2 weeks prior to crystallization. The various protein-ligand complexes were then crystallized via the sitting drop vapor diffusion method using a 1:1 ratio of protein to well solution (total drop volume of $4 \mu \mathrm{L}$ ) at room temperature. Once grown (usually for $2-4$ weeks), the crystals were mounted, transferred to a cryoprotectant solution equivalent to the well solution with $20 \%$ ethylene glycol, and then immediately flash-cooled by immersion in liquid nitrogen. The specific crystallization condition for each of the protein-ligand complexes can be found in Table 1.

\section{Synthesis of Biotin Methyl Ester}

D-(+)-Biotin (5.00 g, $20.5 \mathrm{mmol}, 10.25$ equiv) and $p$-toluenesulfonic acid (monohydrate) $(0.38 \mathrm{~g}, 2.0 \mathrm{mmol}, 1.00$ equiv) were dissolved in dry methanol $(80 \mathrm{~mL})$ and refluxed for 48 h. The solution was then cooled at $4{ }^{\circ} \mathrm{C}$ overnight, resulting in the formation of crystals that were filtered and dried in vacuo to yield biotin methyl ester as a colorless solid $3.9 \mathrm{~g} \mathrm{(74 \% ):}$ $R_{f}=0.37\left(95: 5 \mathrm{CH}_{2} \mathrm{Cl}_{2}: \mathrm{MeOH}\right) ;{ }^{1} \mathrm{H} \mathrm{NMR}\left(\mathrm{CDCl}_{3}, 400 \mathrm{MHz}\right) \delta 1.38-1.55(\mathrm{~m}, 2 \mathrm{H}), 1.60$ $1.78(\mathrm{~m}, 4 \mathrm{H}), 2.35$ (t, $J=7.4 \mathrm{~Hz}, 2 \mathrm{H}), 2.74(\mathrm{~d}, J=12.8 \mathrm{~Hz}, 1 \mathrm{H}), 2.92(\mathrm{dd}, J=12.8,4.9 \mathrm{~Hz}$, $1 \mathrm{H}), 3.10-3.19(\mathrm{~m}, 1 \mathrm{H}), 3.67(\mathrm{~s}, 3 \mathrm{H}), 4.25-4.33(\mathrm{~m}, 1 \mathrm{H}), 4.47-4.56(\mathrm{~m}, 1 \mathrm{H}), 5.43(\mathrm{~s}, 1 \mathrm{H})$, $5.87(\mathrm{~s}, 1 \mathrm{H}) ;{ }^{13} \mathrm{C} \mathrm{NMR}\left(\mathrm{CDCl}_{3}, 100 \mathrm{MHz}\right) \delta 24.8,28.2,28.3,33.7,40.6,51.6,55.4,60.1$, 61.9, 163.6, 174.2; HRMS (ESI-TOF) calcd for $\mathrm{C}_{11} \mathrm{H}_{19} \mathrm{~N}_{2} \mathrm{O}_{3} \mathrm{~S}(\mathrm{M}+\mathrm{H})^{+} \mathrm{m} / z$ 259.1111, observed $\mathrm{m} / \mathrm{z} 259.1119$. 


\section{Synthesis of N1'-Methoxycarbonyl Biotin Methyl Ester}

Biotin methyl ester (6.45 g, $0.025 \mathrm{~mol}, 1$ equiv) and methyl chloroformate ( $90 \mathrm{~mL}, 110.07$

$\mathrm{g}, 1.165 \mathrm{~mol}, 46.6$ equiv) were dissolved in $\mathrm{CHCl}_{3}(140 \mathrm{~mL})$ and refluxed for $72 \mathrm{~h}$, after which excess $\mathrm{CHCl}_{3}$ and methyl chloroformate were removed by distillation. Hot ethyl acetate was added to the remaining mixture while it was being stirred until a colorless precipitate formed. The precipitate was filtered and washed, and the resulting solid was purified by flash chromatography on silica gel eluting with a 95:5 $\mathrm{CHCl}_{3} / \mathrm{MeOH}$ solvent. The resulting oil was dissolved in a minimal amount of hot methanol, at which point water was added dropwise until the solution turned cloudy. The solution was then cooled to room temperature and placed in a freezer overnight. The resulting crystals were filtered, dried in vacuo, and recrystallized to yield $\mathrm{N1}^{\prime}$-methoxycarbonyl biotin methyl ester as a colorless solid (5.2 g, 66\%): $R_{f}=0.73(1: 1 \mathrm{Hex}: E t O A c) ;{ }^{1} \mathrm{H} \mathrm{NMR}\left(\mathrm{CDCl}_{3}, 400 \mathrm{MHz}\right) \delta 1.38-1.56$ (m, 2H), 1.59-1.78 (m, 4H), $2.34(\mathrm{t}, J=7.4 \mathrm{~Hz}, 2 \mathrm{H}), 3.01(\mathrm{dd}, J=13.6,5.3 \mathrm{~Hz}, 1 \mathrm{H}), 3.13$ (d, $J=13.6 \mathrm{~Hz}, 1 \mathrm{H}), 3.15-3.23(\mathrm{~m}, 1 \mathrm{H}), 3.67(\mathrm{~s}, 3 \mathrm{H}), 3.86(\mathrm{~s}, 3 \mathrm{H}), 4.18-4.24(\mathrm{~m}, 1 \mathrm{H}), 4.79-$ $4.88(\mathrm{~m}, 1 \mathrm{H}), 6.49(\mathrm{~s}, 1 \mathrm{H}) ;{ }^{13} \mathrm{C} \mathrm{NMR}\left(\mathrm{CDCl}_{3}, 100 \mathrm{MHz}\right) \delta 24.6,28.0,28.2,33.5,38.7,51.6$, 53.6, 55.3, 57.6, 62.8, 152.5, 155.8, 174.0; HRMS (ESI-TOF) calcd for $\mathrm{C}_{13} \mathrm{H}_{21} \mathrm{~N}_{2} \mathrm{O}_{5} \mathrm{~S}(\mathrm{M}+$ $\mathrm{H})^{+} \mathrm{m} / \mathrm{z} 317.1166$, observed $\mathrm{m} / \mathrm{z} 317.1166$.

\section{X-ray Data Collection, Structure Determination, and Refinement}

X-ray diffraction data were collected at Advanced Photon Source (APS) beamline NE-CAT 24-ID-E or NE-CAT 24-ID-C equipped with an ADSC Q315r or Dectris Pilatus 6M detector, respectively. The data were processed and scaled using XDS ${ }^{14}$ and Scala. ${ }^{15}$ All of the crystals were in space group $\mathrm{P6}_{4}$, where the asymmetric unit contained a monomer of the biotin carboxylase homodimer. Phases were obtained by molecular replacement using Phaser ${ }^{16}$ and the homodimer of E. coli biotin carboxylase [Protein Data Bank (PDB) entry 1DV2] as a search model. The molecular replacement solution was further refined using several cycles of phenix.refine ${ }^{16}$ for all the structures except the one with ADP and $\mathrm{N}^{\prime}$ methoxycarbonyl biotin methyl ester bound, which was refined using REFMAC. ${ }^{17}$ Manual rebuilding was performed in COOT. ${ }^{18}$ All water molecules and ions added were manually verified after the final refinement. The data collection and refinement statistics for each of the structures are listed in Table 1.

\section{RESULTS}

\section{Structures of Biotin Carboxylase Bound to Substrates}

Biotin carboxylase from $H$. inf luenzae was cocrystallized with the stable ATP analogue AMPPCP and $\mathrm{HCO}_{3}{ }^{-}$. The structure was determined and refined to a resolution of $1.69 \AA$. Consistent with the other structures of biotin carboxylase with nucleotide bound, the Bdomain is in the closed conformation. The electron density corresponding to AMPPCP and $\mathrm{HCO}_{3}{ }^{-}$is shown in Figure 3A. This is the first structure of biotin carboxylase with the substrates ATP (or in this case a stable analogue of ATP) and bicarbonate bound in the active site.

AMPPCP bound to biotin carboxylase where every other nucleotide has been observed to bind. Details about nucleotide binding in biotin carboxylase, including the amino acids 
involved, have been extensively reviewed. ${ }^{7}$ The bicarbonate ion binds in the active site where there are several positively charged amino acids, specifically, R292, R338, and K238 (Figure 3B). In addition, the side chain of E296 and the peptide NH group of V295 are within hydrogen bonding distance of bicarbonate (Figure 3B). The binding site for the bicarbonate ion confirms an earlier structure (PDB entry 3G8C) of biotin carboxylase that had ADP, a product of the reaction, and bicarbonate bound to the enzyme. ${ }^{13}$ An intriguing aspect of the bicarbonate/AMPPCP structure described here (PDB entry 4MV3) is that when it is superimposed with the original structure of biotin carboxylase (PDB entry 1BNC), which contained a phosphate ion in the active site that originated from the crystallization solution, ${ }^{10,11}$ the bicarbonate and phosphate ions occupy the exact same binding site (Figure 3C) and, as such, utilize the same cohort of amino acids for binding.

The structure of biotin carboxylase bound to AMPPCP and $\mathrm{HCO}_{3}{ }^{-}$provides the structural context for understanding why hydrolysis of ATP in the presence of $\mathrm{HCO}_{3}{ }^{-}$to form the carboxyphosphate is very slow $\left(k_{\text {cat }}=0.07 \mathrm{~min}^{-1}\right) .{ }^{19}$ The distance between the closest oxygen on $\mathrm{HCO}_{3}{ }^{-}$and the phosphorus atom of the $\gamma$-phosphate group of AMPPCP is $5.8 \AA$ (Figure 3A). This large distance between the two reactants is important physiologically because it ensures that ATP does not undergo any appreciable reaction with $\mathrm{HCO}_{3}{ }^{-}$in the absence of biotin. It is important to point out that the structure of AMPPCP and the $\mathrm{HCO}_{3}{ }^{-}$ does not contain any $\mathrm{Mg}^{2+}$ ions that are required for enzymatic activity. ${ }^{6}$ However, a superimposition of the AMPPCP and the $\mathrm{HCO}_{3}{ }^{-}$structure with biotin carboxylase structures that contained AMPPCP and one $\mathrm{Mg}^{2+}(\mathrm{PDB}$ entry $4 \mathrm{MV} 4)$ and two $\mathrm{Mg}^{2+}$ ions (PDB entry $2 \mathrm{VPQ})^{12}$ revealed that the distances between an oxygen of $\mathrm{HCO}_{3}{ }^{-}$and the phosphorus atom of the $\gamma$-phosphate group of AMPPCP were 6.3 and $4.9 \AA$, respectively. Thus, even in the presence of $\mathrm{Mg}^{2+}$, the distance between AMPPCP and the $\mathrm{HCO}_{3}{ }^{-}$is still not sufficiently short for reaction.

The substrate $\mathrm{HCO}_{3}{ }^{-}$can apparently bind to the enzyme in the absence of AMPPCP (and by inference ATP) because a $1.98 \AA$ resolution structure of biotin carboxylase with only $\mathrm{HCO}_{3}{ }^{-}$bound (PDB entry 4MV9) (Figure 3D) revealed that it binds in the same position as when AMPPCP is present (PDB entry 4MV3). The observation that $\mathrm{HCO}_{3}{ }^{-}$can bind in the absence of the nucleotide strongly suggests that $\mathrm{HCO}_{3}{ }^{-}$and ATP bind to biotin carboxylase by a random kinetic mechanism as originally proposed by Tipton and Cleland. ${ }^{20}$

\section{Structures of Biotin Carboxylase Bound to Carboxyphosphate Analogues}

After substrate binding, the first step in catalysis is the reaction of $\mathrm{HCO}_{3}{ }^{-}$with ATP to form carboxyphosphate. ${ }^{21}$ Carboxyphosphate (Figure 1A) is a very unstable molecule with an estimated half-life of $70 \mathrm{~ms} .^{22}$ Therefore, biotin carboxylase was cocrystallized with the stable analogues of carboxyphosphate, phosphonoacetamide (Figure 1B), and phosphonoformate (Figure 1C). The structures of biotin carboxylase bound to phosphonoacetamide and phosphonoformate were determined and refined to resolutions of 1.77 and $1.73 \AA$, respectively. The electron density corresponding to phosphonoacetamide and phosphonoformate is shown in panels A and B of Figure 4. The phosphonate moieties of both phosphonoacetamide and phosphonoformate bind in the same position and orientation. Moreover, the phosphonate moieties of both phosphonoacetamide and phosphonoformate 
bound in the same position as bicarbonate (PDB entries 4MV3 and 4MV9) and phosphate (PDB entry 1DV1). As such, the phosphonate moiety interacts with the same set of residues as bicarbonate and phosphate, namely, R292, K238, E296, and the main chain amide of V295 (Figure 4C). The side chain of R338 interacts with the carbonyl oxygen of phosphonoacetamide (Figure 4C).

These structural observations are consistent with kinetic data derived from an alternate reaction catalyzed by biotin carboxylase in which the phosphoryl group of carbamoyl phosphate (Figure 1D) is transferred to ADP to form ATP and carbamic acid. ${ }^{23}$ Because carbamoyl phosphate is a structural analogue of carboxyphosphate, this reaction was considered to be the reverse reaction catalyzed by biotin carboxylase and was the first piece of evidence suggesting a carboxyphosphate intermediate. ${ }^{23}$ When bicarbonate was used as an inhibitor, it exhibited competitive inhibition with respect to carbamoyl phosphate with a $K_{\mathrm{i}}$ value of $0.66 \pm 0.11 \mathrm{mM}$, which is similar to the $K_{\mathrm{m}}$ value for bicarbonate of $0.37 \pm 0.04$ mM. ${ }^{19}$ When phosphate was used as an inhibitor, it also exhibited competitive inhibition with respect to carbamoyl phosphate with a $K_{\mathrm{i}}$ value of $2.2 \pm 0.2 \mathrm{mM}$. Thus, the kinetic data confirm the structural findings that bicarbonate and phosphate bind in the same place in the active site.

The orientation of phosphonoacetamide in the active site is also consistent with this alternate reaction. When the structure of biotin carboxylase with phosphonoacetamide bound is superimposed with a structure (PDB entry 4MV1) that contained phosphate and ADP, the phosphonate moiety overlays with phosphate while the carbamate moiety is pointed in the opposite direction of ADP (Figure 4D). This is the orientation of phosphonoacetamide in the active site that would be expected because it allows the $\beta$-phosphorus atom of ADP to react with the phosphate of carbamoyl phosphate to form ATP. The distance between the phosphonate oxygen in phosphonoacetamide and the $\beta$-phosphorus atom of ADP is $7.2 \AA$. This large distance is consistent with the relatively low turnover number $\left(50 \mathrm{~min}^{-1}\right)$ for the reverse reaction of biotin carboxylase. ${ }^{19}$ However, the addition of biotin does significantly increase the rate of the reverse reaction. ${ }^{19}$ A possible molecular basis for stimulation of the reaction by biotin can be seen if the structure of biotin carboxylase bound to phosphonoacetamide is superimposed on the structure of the enzyme bound to biotin (PDB entry 3G8C). ${ }^{13}$ The acetamide moiety of phosphonoacetamide overlays perfectly with the ureido ring of biotin (Figure 4E), which is not surprising given the structural similarity between the two. Biotin could stimulate the rate of reaction of carbamoyl phosphate with ADP by displacing carbamoyl phosphate from its binding site pushing it closer to ADP. Thus, because of the overlapping binding sites of biotin and phosphonoacetamide (and by inference carbamoyl phosphate), it is not clear if this is the binding site for the carboxyphosphate intermediate. This uncertainty is also supported by the fact that phosphonoacetamide does not align with phosphonoacetate, another structural analogue of carboxyphosphate, bound to pyruvate carboxylase, a related biotin-dependent enzyme (Figure 4F). ${ }^{24}$ In fact, phosphonoacetate was found to assume two possible orientations in pyruvate carboxylase (Figure $4 \mathrm{~F}){ }^{24}$ 


\section{Structures of Biotin Carboxylase Bound to Products}

After carboxyphosphate formation, the carboxyl group is transferred to the $1^{\prime}$ nitrogen of biotin to form the product carboxybiotin (Figure 1E). Carboxybiotin is a relatively unstable molecule with a half-life of $2.5 \mathrm{~h}$ at $\mathrm{pH} 7.0,{ }^{25}$ which makes it unsuitable for crystallographic trials. Therefore, the stable methyl ester of carboxybiotin, $\mathrm{N}^{\prime}$-methoxycarbonyl biotin methyl ester (Figure 1F), was used for structural analysis. N1'-Methoxycarbonyl biotin methyl ester was synthesized by a modification of the procedure described by Knappe et al. ${ }^{26}$ and cocrystallized with biotin carboxylase along with another product of the reaction, ADP. The structure was determined and refined to a resolution of $1.98 \AA$. The electron density corresponding to $\mathrm{N} 1^{\prime}$-methoxycarbonyl biotin methyl ester is shown in Figure 5A. The electron density for the valeric acid side chain of biotin is discontinuous, presumably because of flexibility caused by the side chain's lack of interactions with active site amino acids. In contrast, the electron density for the $1^{\prime}$ nitrogen of the ureido ring and the methoxycarbonyl group is better defined because of multiple interactions with residues in the active site of biotin carboxylase. The methyl ester moiety corresponding to the carboxyl group of carboxybiotin binds in the same position occupied by $\mathrm{HCO}_{3}{ }^{-}$and phosphate and, as such, interacts with the same set of amino acids, namely, R338, K238, and R292 (Figure 5B). The side chain of E296 also interacts with the carboxymethyl ester moiety. In addition, R292 interacts with the carbonyl oxygen of biotin while R338 is close enough to hydrogen bond to the sulfur atom in the thiophene ring of biotin (Figure 5B). The other notable feature of the carboxybiotin analogue bound to biotin carboxylase is that the carboxymethyl ester moiety is rotated approximately $90^{\circ}$ with respect to the plane of the ureido ring of biotin (Figure 5B). In contrast, the crystal structure of $\mathrm{N} 1^{\prime}$-methoxycarbonyl biotin methyl ester not bound to protein shows the carboxymethyl ester moiety is coplanar with the ureido ring of biotin. ${ }^{27}$ It is important to note that the methyl group of the carboxymethyl ester moiety does not interact with any active site amino acids and, therefore, is unlikely to influence the orthogonal orientation relative to the ureido ring of biotin.

Biotin carboxylase has an ordered release of products with carboxybiotin leaving first followed by phosphate and then ADP. ${ }^{20}$ Therefore, once carboxybiotin is released, the final structure of biotin carboxylase shows the position of the last two products of the reaction, ADP and $P_{i}$. Biotin carboxylase was cocrystallized with ADP and $P_{i}$, and the structure was determined and refined to a resolution of $1.91 \AA$. The electron density corresponding to $\mathrm{ADP}$ and $\mathrm{P}_{\mathrm{i}}$ is shown in Figure 5C. As expected, the product ADP binds in the nucleotide binding pocket, while phosphate binds to the same site as the phosphate binding site observed in the original structure of biotin carboxylase, ${ }^{10}$ which is also the $\mathrm{HCO}_{3}{ }^{-}$binding site. As such, the phosphate interacts with the same set of amino acids, namely, R292, K238, R338, and E296, as bicarbonate.

Thus, all the structures described above have a common theme. That is, biotin carboxylase appears to utilize the same set of amino acids to bind the substrate bicarbonate, the reaction intermediate carboxyphosphate, and the products carboxybiotin and phosphate. The implications of this observation for the catalytic mechanism of biotin carboxylase are discussed below. 


\section{DISCUSSION}

Interpretation of these structures in terms of the catalytic mechanism of biotin carboxylase begins with the fact that the enzyme needs a source of $\mathrm{CO}_{2}$. Bicarbonate was selected as the source of $\mathrm{CO}_{2}$ for biotin carboxylase for two possible reasons. First, the concentration of bicarbonate is much higher than that of $\mathrm{CO}_{2}$ at physiological $\mathrm{pH}$ values $\left(10 \mu \mathrm{M} \mathrm{CO}_{2}\right.$ vs 50 $500 \mu \mathrm{M}$ bicarbonate). ${ }^{28}$ Most importantly, the $K_{\mathrm{m}}$ value for bicarbonate in biotin carboxylase is $0.37 \pm 0.04 \mathrm{mM},{ }^{19}$ which is in the concentration range of bicarbonate found at physiological $\mathrm{pH}$ values. Second, bicarbonate has a negative charge at physiological $\mathrm{pH}$, thereby aiding in binding to the enzyme. The structures presented in this report indicate that biotin carboxylase uses a structural motif that binds phosphate to also bind bicarbonate. From an evolutionary perspective, this is a simple, straightforward solution for bicarbonate binding because it capitalizes on the structural similarity between bicarbonate and phosphate and utilizes a phosphate binding site that most likely already existed in the ATP-grasp superfamily of enzymes.

Once the substrates are bound to biotin carboxylase, the first catalytic step is the reaction of bicarbonate with the $\gamma$-phosphate group of ATP to form carboxyphosphate. This reaction serves to activate the unreactive bicarbonate for nucleophilic attack by the $1^{\prime}$ nitrogen of biotin. The structure of biotin carboxylase with bicarbonate and AMPPCP represents the ground state of the reaction because the distance between the closest oxygen of bicarbonate and the $\gamma$-phosphorus atom is $5.8 \AA$. This distance between the reactants is necessary to prevent unproductive hydrolysis of ATP in the absence of the acceptor biotin. After biotin binding, the enzyme must compress bicarbonate and ATP to react and form carboxyphosphate. The mechanism of the compression (e.g., conformational change) is not known; however, the reaction of bicarbonate and ATP to form carboxyphosphate may be rate-determining. This is because the reaction catalyzed by biotin carboxylase exhibits a significant inverse kinetic solvent isotope effect; ${ }^{\mathrm{D}_{2} \mathrm{O}}\left(V_{\max } / K_{\mathrm{m}}\right)=0.45 \pm 0.1 .{ }^{29,30}$ The inverse kinetic solvent isotope effect was originally attributed to a cysteine residue acting as a catalytic base to remove the proton from the $1^{\prime}$ nitrogen of biotin. ${ }^{29}$ However, several lines of evidence have discounted this interpretation. ${ }^{30}$ Instead, the inverse solvent isotope effect observed may be due to the displacement of water from the $\mathrm{Mg}^{2+}$ ions when bicarbonate reacts with ATP. The structure of biotin carboxylase from Staphylococcus aureus bound to AMPPNP and two $\mathrm{Mg}^{2+}$ ions shows that one of the $\mathrm{Mg}^{2+}$ ions is coordinated to two water molecules ${ }^{12}$ and removal of water coordinated to metal ions exhibits an inverse kinetic solvent isotope effect. ${ }^{31-33}$ Therefore, the inverse kinetic solvent isotope effect observed may be due to the displacement of water from the $\mathrm{Mg}^{2+}$ ions when bicarbonate reacts with ATP. If formation of the unstable carboxyphosphate is rate-determining, then transfer of the carboxyl group to the $1^{\prime}$ nitrogen of biotin is likely to occur very fast.

There are two competing theories for the transfer of the carboxyl group of carboxyphosphate to the $1^{\prime}$ nitrogen of biotin. One postulates that carboxyphosphate decomposes in the active site to form phosphate and $\mathrm{CO}_{2}$, which is the carboxylating agent. ${ }^{4}$ The other mechanism involves direct attack of the $1^{\prime}$ nitrogen of biotin on the carboxyl group of carboxyphosphate, which would require biotin carboxylase to accommodate and stabilize a dianionic tetrahedral structure. ${ }^{4}$ The structure of the enzyme bound to the carboxybiotin 
analogue $\mathrm{N} 1^{\prime}$-methoxycarbonyl biotin methyl ester reveals the region of the active site where biotin carboxylation likely occurs, which also turns out to be the phosphate binding site (Figure 5B). The positively charged amino acids that interact with the tetrahedral dianionic phosphate could also interact and stabilize a tetrahedral dianionic transition state (Figure 6). Consistent with this model is that mutation of residues that interact with phosphate and the carboxybiotin analogue $\mathrm{N1}^{\prime}$-methoxycarbonyl biotin methyl ester, R338 and $\mathrm{K} 238$, resulted in decreases in activity of several hundred-fold (R338S $)^{34}$ to a thousandfold (K238Q) ${ }^{30}$ Most importantly, the mutant enzymes exhibited a significant uncoupling of ATP hydrolysis from carboxylation of biotin, consistent with a role in the transfer of the carboxyl group from carboxyphosphate to biotin. It is important to note that mutational analysis of residues homologous to R338, K238, and R292 in the biotin-dependent enzyme pyruvate carboxylase were also found to be critical for transfer of the carboxyl group from carboxyphosphate to biotin. ${ }^{5}$ Residues R338 and K238 could not only neutralize the dianionic transition state but also rotate the carboxyl group orthogonal to the plane of the ureido ring. This is the first experimental evidence that supports the proposal by Gregory et al. ${ }^{35}$ that biotin-dependent carboxylases must rotate the carboxyl group of carboxybiotin out of the plane of the ureido ring for carboxylation and decarboxylation of biotin to occur. The structure of biotin carboxylase bound to N1'-methoxycarbonyl biotin methyl ester also shows that R292 interacts with the carbonyl oxygen of the biotin. This is consistent with the observation that the R292A mutant decreased activity 100-fold but did not uncouple ATP hydrolysis from biotin carboxylation. ${ }^{19}$ It is important to point out that R292 is the only residue that interacts with the carbonyl oxygen of biotin that forms an oxyanion during the carboxylation reaction. ${ }^{4}$ Perrin and Dwyer have pointed out that complete neutralization or protonation of the carbonyl oxyanion would actually inhibit carboxylation by decreasing the nucleophilicity of the $1^{\prime}$ nitrogen of biotin. ${ }^{36}$ Thus, having only a single amino acid interact with the carbonyl oxygen of biotin is consistent with this theory.

The formation of the oxyanion of biotin during catalysis must coincide with the removal of the proton from $\mathrm{N1}^{\prime}$ of biotin. The interaction of R292 with the carbonyl oxygen of biotin helps to lower the $\mathrm{p} K_{\mathrm{a}}$ of $\mathrm{N}^{\prime}$ of biotin, facilitating abstraction by an active site base. ${ }^{36}$ The closest amino acid that could act as a base is E296; however, mutation of this residue yielded an enzyme with $90 \%$ of the activity of the wild type. ${ }^{13}$ Therefore, the prevailing model is that biotin carboxylase utilizes substrate-assisted catalysis whereby the phosphate of carboxyphosphate abstracts the proton from biotin, generating dibasic phosphate, which is a good leaving group. ${ }^{5}$

If this is the mechanism for proton abstraction, then what is the position of biotin during carboxyl transfer? The structure of biotin carboxylase with biotin bound can be considered to represent the ground state of substrate binding, ${ }^{13}$ while the $\mathrm{N} 1^{\prime}$-methoxycarbonyl biotin methyl ester structure represents the ground state for product binding. When the two structures of biotin are superimposed, they occupy the same place in the active site but with different orientations (Figure 7). Therefore, the position of biotin in the transition state is likely to be somewhere between biotin and the carboxybiotin analogue $\mathrm{N1}^{\prime}$ methoxycarbonyl biotin methyl ester. It should be noted that the position of biotin bound to the biotin carboxylase domain of pyruvate carboxylase is $5.7 \AA$ from the biotin observed in 
the two structures of $E$. coli biotin carboxylase and, therefore, will not be considered further. Given the short half-life of carboxyphosphate of $70 \mathrm{~ms},{ }^{22}$ the mechanism proposed here for the direct transfer of the carboxyl group from carboxyphosphate to biotin is likely to be very fast, which is consistent with the very small carbon isotope effect $\left[{ }^{13}(V / K)=1.007\right]$ for biotin carboxylase ${ }^{29}$ If carboxyl transfer were the rate-limiting step in catalysis, the isotope effect would be $\sim 1.04$.

There is precedent for the direct attack model for carboxyl transfer described here. First, model chemical studies have shown that the conjugate base of urea can act as a nucleophile on an ionized carboxyl group with general acid catalysis required to stabilize the dianionic intermediate. ${ }^{37}$ Second, the direct attack model for carboxyl transfer is consistent with biotin carboxylase being a member of the ATP-grasp superfamily of enzymes. For instance, in the reaction catalyzed by another member of that superfamily, D-Ala-D-Ala ligase, ATP reacts with the carboxyl group of D-Ala to form an acylphosphate. The amino group of the second D-Ala then directly attacks the carbonyl group of the acylphosphate intermediate. ${ }^{38}$ In fact, for the overwhelming majority of enzymes in the ATP-grasp superfamily, the nucleophile attacks the acylphosphate intermediate directly because the intermediate does not decompose in the active site. Moreover, in the only other ATP-grasp enzyme that also utilizes ATP to activate bicarbonate, carbamoyl phosphate synthetase, it has been shown experimentally that the ammonia attacks the carboxyphosphate intermediate directly and not via $\mathrm{CO}_{2} \cdot{ }^{39}$ Thus, the structural observations in this report suggesting direct transfer of the carboxyl group from carboxyphosphate to biotin are consistent with the chemical mechanisms of the other ATP-grasp enzymes.

In summary, having bicarbonate and phosphate share a binding site was very parsimonious from an evolutionary point of view. A single structural motif, the phosphate binding site, not only doubles as a binding site for bicarbonate but also serves as the binding site for the tetrahedral transition state for carboxylation. Using the same set of active site amino acids to perform multiple functions means these residues are critical for catalysis and any mutation would cripple the enzymatic function. As such, the phosphate/bicarbonate binding site is an ideal site for developing ligands that can act as inhibitors. In turn, these inhibitors can be tested for antibacterial activity because biotin carboxylase has been validated as a target for antibiotic development. ${ }^{40-42}$ Lastly, as atmospheric $\mathrm{CO}_{2}$ levels continue to rise, there is a growing need for small synthetic catalysts that bind $\mathrm{CO}_{2} / \mathrm{HCO}_{3}{ }^{-}$and convert it into a useful energy source. ${ }^{43}$ Perhaps the mechanism by which nature binds bicarbonate in biotin carboxylase can serve as a framework for designing and developing these synthetic catalysts.

\title{
Acknowledgments
}

\author{
Funding \\ This work includes research conducted at the Northeastern Collaborative Access Team beamlines (24ID-C and \\ 24ID-E at the Advanced Photon Source), which are funded by the National Institute of General Medical Sciences \\ (P41 GM103403) of the National Institutes of Health. The Pilatus 6M detector on 24ID-C is funded by NIH-ORIP \\ HEI Grant S10 RR029205. Use of the Advanced Photon Source, an Office of Science User Facility operated for the \\ U.S. Department of Energy by Argonne National Laboratory, is supported by Contract DE-AC02-06CH11357.
}


We thank Ashley Broussard for her expert contribution to the design of the figures and Molly Silvers for determining the NMR spectra for biotin methyl ester and $\mathrm{N}^{\prime}{ }^{\prime}$-methoxycarbonyl biotin methyl ester.

\section{References}

1. Moss J, Lane MD. The Biotin-Dependent Enzymes. Adv Enzymol Relat Areas Mol Biol. 1971; 35:321-442. [PubMed: 4150153]

2. Tanabe T, Wada K, Okazaki T, Numa S. Acetyl-coenzyme-A carboxylase from rat liver. Subunit structure and proteolytic modification. Eur J Biochem. 1975; 57:15-24. [PubMed: 240717]

3. Cronan JE Jr, Waldrop GL. Multi-subunit acetyl-CoA carboxylases. Prog Lipid Res. 2002; 41:407435. [PubMed: 12121720]

4. Knowles JR. The Mechanism of Biotin-Dependent Enzymes. Annu Rev Biochem. 1989; 58:195221. [PubMed: 2673009]

5. Zeczycki TN, Menefee AL, Adina-Zada A, Jitrapakdee S, Surinya KH, Wallace JC, Attwood PV, St Maurice M, Cleland WW. Novel insights into the biotin carboxylase domain reactions of pyruvate carboxylase from Rhizobium etli. Biochemistry. 2011; 50:9724-9737. [PubMed: 21957995]

6. Climent I, Rubio V. ATPase Activity of Biotin Carboxylase Provides Evidence for Initial Activation of $\mathrm{HCO}_{3}{ }^{-}$by ATP in the Carboxylation of Biotin. Arch Biochem Biophys. 1986; 251:465-470. [PubMed: 2948446]

7. Waldrop GL, St Maurice M, Holden HM. The Enzymes of Biotin Dependent $\mathrm{CO}_{2}$ Metabolism: What Structures Reveal about their Reaction Mechanisms. Protein Sci. 2012; 21:1597-1619. [PubMed: 22969052]

8. Fawaz MV, Topper ME, Firestine SM. The ATP-grasp enzymes. Bioorg Chem. 2011; 39:185-191. [PubMed: 21920581]

9. Galperin MY, Koonin EV. (1997) A Diverse Superfamily of Enzymes with ATP-Dependent Carboxylate-Amine/Thiol Ligase Activity. Protein Sci. 1997; 6:2639-2643. [PubMed: 9416615]

10. Waldrop GL, Rayment I, Holden HM. Three-Dimensional Structure of the Biotin Carboxylase Subunit of Acetyl-CoA Carboxylase. Biochemistry. 1994; 33:10249-10256. [PubMed: 7915138]

11. Thoden JB, Blanchard CZ, Holden HM, Waldrop GL. Movement of the Biotin Carboxylase BDomain as a Result of ATP Binding. J Biol Chem. 2000; 275:16183-16190. [PubMed: 10821865]

12. Mochalkin I, Miller JR, Evdokimov A, Lightle S, Yan C, Stover CK, Waldrop GL. Structural evidence for substrate-induced synergism and half-sites reactivity in biotin carboxylase. Protein Sci. 2008; 17:1706-1718. [PubMed: 18725455]

13. Chou CY, Yu LP, Tong L. Crystal structure of biotin carboxylase in complex with substrates and implications for its catalytic mechanism. J Biol Chem. 2009; 284:11690-11697. [PubMed: 19213731]

14. Kabsch W. XDS. Acta Crystallogr. 2010; D66:125-132.

15. Evans PR. Scaling and assessment of data quality. Acta Crystallogr. 2006; D62:72-82.

16. Adams PD, Afonine PV, Bunkoczi G, Chen VB, Davis IW, Echols N, Headd JJ, Hung LW, Kapral GJ, Grosse-Kunstleve RW, et al. PHENIX: A comprehensive Python-based system for macromolecular structure solution. Acta Crystallogr. 2010; D66:213-221.

17. Bailey S. The Ccp4 suite: Programs for protein crystallography. Acta Crystallogr. 1994; D50:760 763.

18. Emsley P, Cowtan K. Coot: Model-building tools for molecular graphics. Acta Crystallogr. 2004; D60:2126-2132.

19. Blanchard CZ, Lee YM, Frantom PA, Waldrop GL. Mutations at four active site residues of biotin carboxylase abolish substrate-induced synergism by biotin. Biochemistry. 1999; 38:3393-3400. [PubMed: 10079084]

20. Tipton PA, Cleland WW. Catalytic mechanism of biotin carboxylase: Steady-state kinetic investigations. Biochemistry. 1988; 27:4317-4325. [PubMed: 2971391]

21. Ogita T, Knowles JR. On the intermediacy of carboxyphosphate in biotin-dependent carboxylations. Biochemistry. 1988; 27:8028-8033. [PubMed: 2976600] 
22. Sauers CK, Jencks WP, Groh S. Alcohol-Bicarbonate-Water System. Structure-Reactivity Studies on the Equilibriums for Formation of Alkyl Monocarbonates and on the Rates of Their Decomposition in Aqueous Alkali. J Am Chem Soc. 1975; 97:5546-5553.

23. Polakis SE, Guchhait RB, Lane MD. On the Possible Involvement of a Carbonyl Phosphate Intermediate in the Adenosine Triphosphate-dependent Carboxylation of Biotin. J Biol Chem. 1972; 247:1335-1337. [PubMed: 4551517]

24. Lietzan AD, Menefee AL, Zeczycki TN, Kumar S, Attwood PV, Wallace JC, Cleland WW, St Maurice M. Interaction between the biotin carboxyl carrier domain and the biotin carboxylase domain in pyruvate carboxylase from Rhizobium etli. Biochemistry. 2011; 50:9708-9723. [PubMed: 21958016]

25. Tipton PA, Cleland WW. Mechanisms of Decarboxylation of Carboxybiotin. J Am Chem Soc. 1988; 110:5866-5869.

26. Knappe J, Ringermann E, Lynen F. Zur Biochemischen Funktion des Biotin. Biochem Z. 1961; 335:168-176. [PubMed: 14457199]

27. Stallings WC, Monti CT, Lane MD, DeTitta GT. Molecular Structure and Intermolecular Interactions of N1'-Methoxycarbonylbiotin Methyl Ester: A Model for Carboxybiotin. Proc Natl Acad Sci USA. 1980; 77:1260-1264. [PubMed: 6929481]

28. Asada, K. Biological Carboxylations in Organic and Bioorganic Chemistry of Carbon Dioxide. Inoue, S.; Yamazaki, N., editors. John Wiley \& Sons; New York: 1982.

29. Tipton PA, Cleland WW. Carbon-13 and Deuterium Isotope Effects on the Catalytic Reactions of Biotin Carboxylase. Biochemistry. 1988; 27:4325-4332. [PubMed: 3048384]

30. Levert KL, Lloyd RB, Waldrop GL. Do cysteine 230 and lysine 238 of biotin carboxylase play a role in the activation of biotin? Biochemistry. 2000; 39:4122-4128. [PubMed: 10747803]

31. Flagg SC, Giri N, Pektas S, Maroney MJ, Knapp MJ. Inverse Solvent Isotope Effects Demonstrate Slow Aquo Release from Hypoxia Inducible Factor-Prolyl Hydroxylase (PDH2). Biochemistry. 2012; 51:6654-6666. [PubMed: 22747465]

32. Harrison RK, Chang B, Niedzwiecki L, Stein RL. Mechanistic studies on the human matrix metalloproteinase stromelysin. Biochemistry. 1992; 31:10757-10762. [PubMed: 1420192]

33. Born TL, Zheng RJ, Blanchard JS. Hydrolysis of N-succinyl-L,L-diaminopimelic acid by the Haemophilus influenza dapE-encoded desuccinylase: Metal activation, solvent isotope effects, and kinetic mechanism. Biochemistry. 1998; 37:10478-10487. [PubMed: 9671518]

34. Sloane V, Waldrop GL. Kinetic characterization of mutations found in propionic acidemia and methylcrotonylglycinuria: Evidence for cooperativity in biotin carboxylase. J Biol Chem. 2004; 279:15772-15778. [PubMed: 14960587]

35. Thatcher GRJ, Poirier R, Kluger R. Enzymic Carboxyl Transfer from N-Carboxybioitn. A Molecular Orbital Evaluation of Conformational Effects in Promoting Reactivity. J Am Chem Soc. 1986; 108:2699-2704.

36. Perrin CL, Dwyer TJ. Proton Exchange in Biotin: A Reinvestigation, with Implications for the Mechanism of $\mathrm{CO}_{2}$ Transfer. J Am Chem Soc. 1987; 109:5163-5167.

37. Blagoeva IB, Pojarlieff IG, Kirby AJ. Intramolecular Nucleophilic Attack on Carboxylate by Ureide Anion. General Acid-Base Catalysis of the Alkaline Cyclisation of 2,2,3,5Tetramethylhydantoic Acid. J Chem Soc, Perkin Trans. 1984; 2:745-751.

38. Fan C, Moews PC, Walsh CT, Knox JR. Vancomycin Resistance: Structure of D-Alanine:DAlanine Ligase at 2.3 Å Resolution. Science. 1994; 266:439-443. [PubMed: 7939684]

39. Gibson GE, Mullins LS, Raushel FM. Carbamoyl Phosphate Synthetase from Escherichia coli Does Not Catalyze the Dehydration of Bicarbonate to Carbon Dioxide. Bioorg Chem. 1998; 26:255-268.

40. Miller JR, Dunham S, Mochalkin I, Banotai C, Bowman M, Buist S, Dunkle B, Hanna D, Harwood HJ, Huband MD, Karnovsky A, Kuhn M, Limberakis C, Liu JY, Mehrens S, Mueller WT, Narasimhan L, Ogden A, Ohren J, Prasad JV, Shelly JA, Skerlos L, Sulavik M, Thomas VH, VanderRoest S, Wang L, Wang Z, Whitton A, Zhu T, Stover CK. A class of selective antibacterials derived from a protein kinase inhibitor pharmacophore. Proc Natl Acad Sci USA. 2009; 106:1737-1742. [PubMed: 19164768] 
41. Mochalkin I, Miller JR, Narasimhan L, Thanabal V, Erdman P, Cox PB, Prasad JV, Lightle S, Huband MD, Stover CK. Discovery of antibacterial biotin carboxylase inhibitors by virtual screening and fragment-based approaches. ACS Chem Biol. 2009; 4:473-483. [PubMed: 19413326]

42. Cheng CC, Shipps GW Jr, Yang Z, Sun B, Kawahata N, Soucy KA, Soriano A, Orth P, Xiao L, Mann P, Black T. Discovery and optimization of antibacterial AccC inhibitors. Bioorg Med Chem Lett. 2009; 19:6507-6514. [PubMed: 19875284]

43. Appel AM, Bercaw JE, Bocarsly AB, Dobbek H, Dupuis M, DuBois DL, Ferry JG, Fujita E, Hille R, Kenis PJA, Kerfeld CA, Morris RH, Peden CHF, Portis AR, Ragsdale SW, Rauchfuss TB, Reek JNH, Seefeldt LC, Thauer RK, Waldrop GL. Frontiers, Opportunities, and Challenges in Biochemical and Chemical Catalysis of $\mathrm{CO}_{2}$ Fixation. Chem Rev. 2013; 113:6621-6658. [PubMed: 23767781] 
A

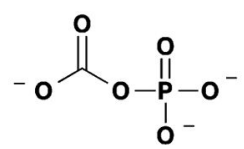

Carboxyphosphate

B<smiles>NC(=O)CP(=O)([O-])[O-]</smiles>

Phosphonoacetamide

C

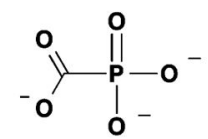

Phosphonoformate
D<smiles>NC(=O)OP(=O)([O-])[O-]</smiles>

Carbamoyl Phosphate

E<smiles>O=C(O)CCCCC1CSCC2C1NC(=O)N2C(=O)[O-]</smiles>

Carboxybiotin

$\mathbf{F}$

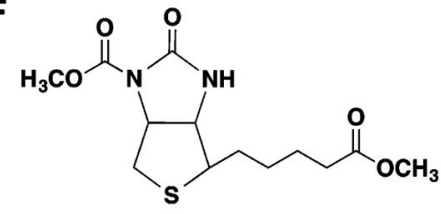

N1'-Methoxycarbonyl Biotin Methyl Ester

Figure 1.

Structures of biotin carboxylase substrates, products, product analogues, the reaction intermediate, and reaction intermediate analogues. 

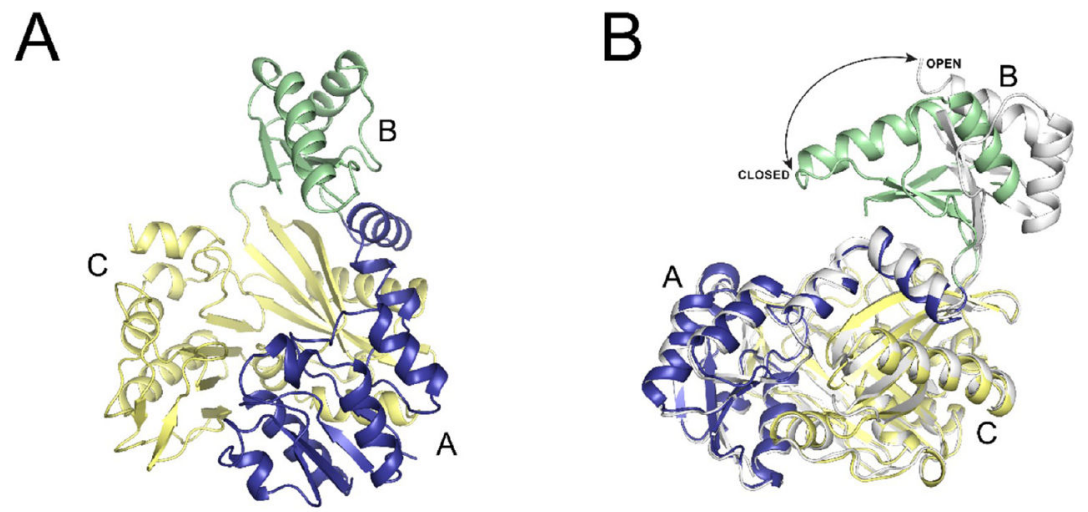

Figure 2.

(A) Ribbon drawing of biotin carboxylase without substrate bound. The three domains are highlighted as the A-domain (deep blue), B-domain (pale green), and C-domain (pale yellow) that will remain consistent throughout the figures. (B) Ribbon drawing of biotin carboxylase without substrates bound, Protein Data Bank entry 1BNC (white), superimposed on biotin carboxylase with AMPPCP and bicarbonate bound, Protein Data Bank entry 4MV3 (colored). 

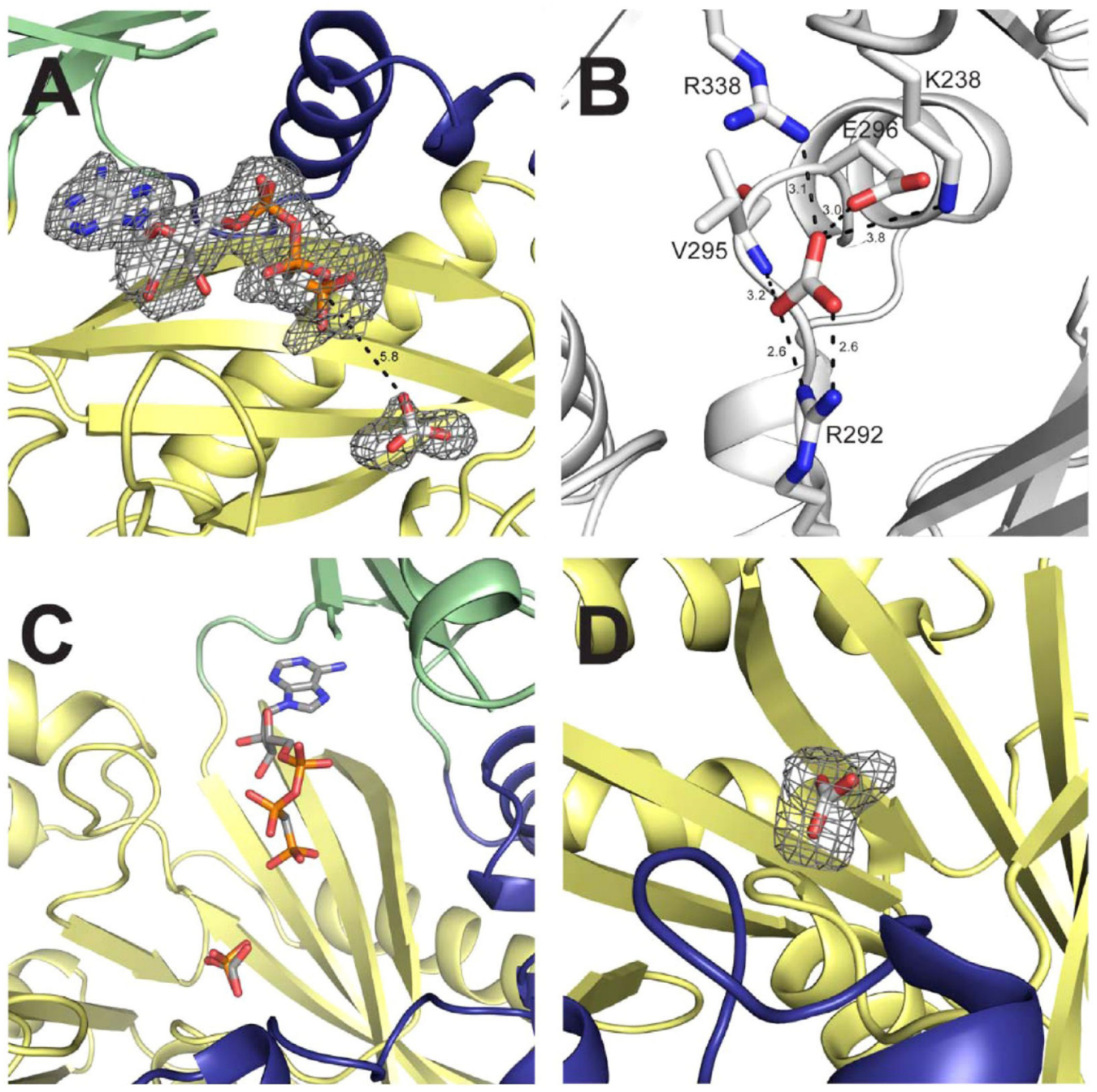

Figure 3.

(A) Electron density corresponding to AMPPCP and bicarbonate. The displayed electron density is a simulated annealing $\left|F_{\mathrm{O}}-F_{\mathrm{c}}\right|$ map contoured at $3 \sigma$ from which the coordinates for the ligands were omitted. The distance between the oxygen of bicarbonate and the $\gamma$ phosphorus atom is in angstroms. (B) Intermolecular interactions between bicarbonate and biotin carboxylase. Possible hydrogen bonds are indicated by dashed lines. (C) Biotin carboxylase bound to AMPPCP and bicarbonate (PDB entry 4MV3) superimposed onto biotin carboxylase with phosphate bound (PDB entry 1BNC). (D) Electron density corresponding to bicarbonate. The displayed electron density is a simulated annealing $\mid F_{\mathrm{O}}-$ $F_{\mathrm{c}}$ map contoured at $3 \sigma$ from which the coordinates for the ligand were omitted. 

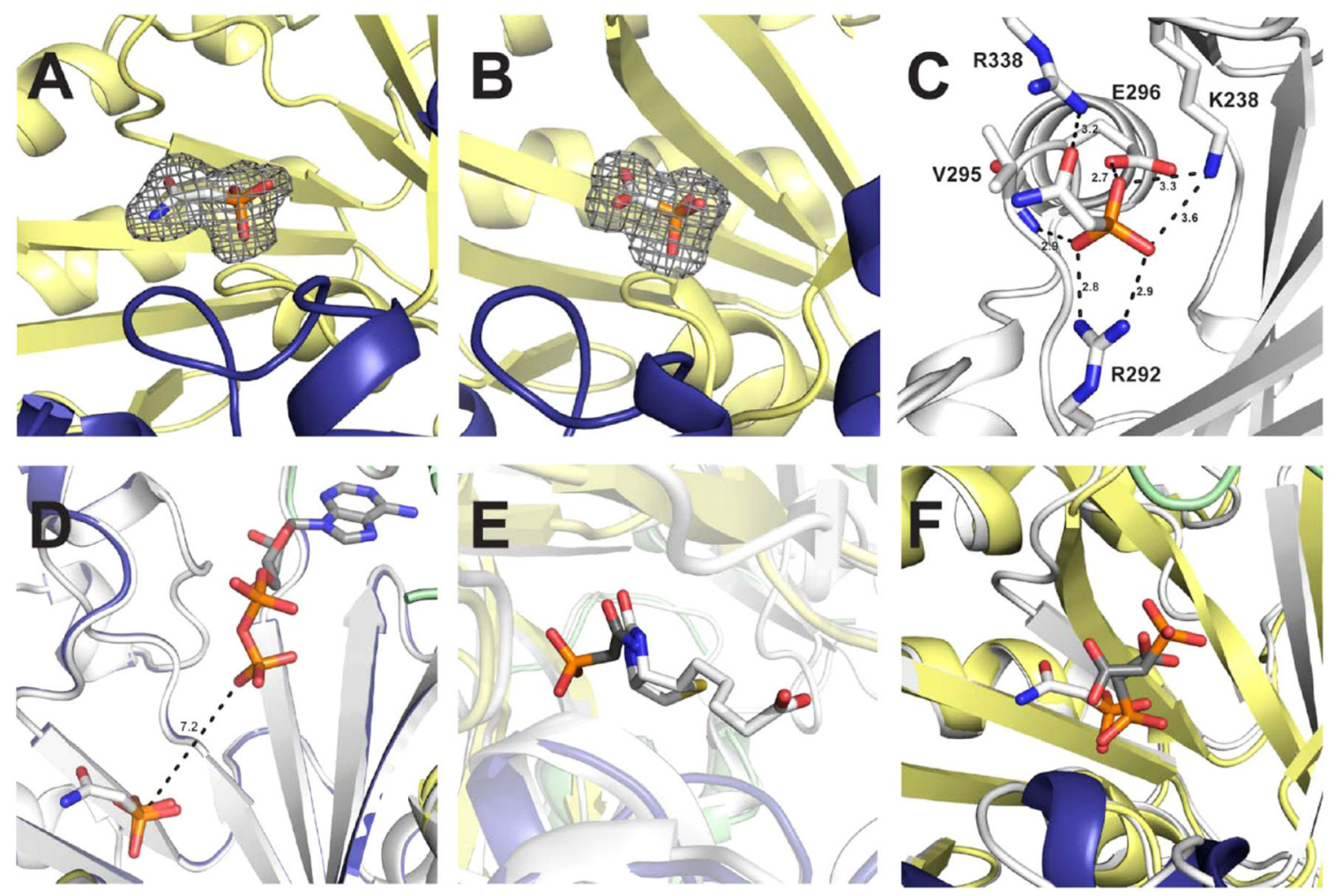

Figure 4.

(A) Electron density corresponding to phosphonoacetamide. The displayed electron density is a simulated annealing $\left|F_{\mathrm{O}}-F_{\mathrm{c}}\right|$ map contoured at $3 \sigma$ from which the coordinates for the ligand were omitted. (B) Electron density corresponding to phosphonoformate. The displayed electron density is a simulated annealing $\left|F_{\mathrm{O}}-F_{\mathrm{c}}\right|$ map contoured at $3 \sigma$ from which the coordinates for the ligand were omitted. (C) Intermolecular interactions between phosphonoacetamide and biotin carboxylase. Possible hydrogen bonds are indicated by dashed lines. (D) Biotin carboxylase bound to phosphonoacetamide (PDB entry 4MV6) superimposed onto biotin carboxylase with phosphate and ADP bound (PDB entry 4MV1). The distance between the oxygen of ADP and the phosphorus atom of phosphonoacetamide is in angstroms. (E) Biotin carboxylase bound to phosphonoacetamide (PDB entry 4MV6) superimposed onto biotin carboxylase with biotin bound (PDB entry 3G8C). (F) Biotin carboxylase bound to phosphonoacetamide (PDB entry 4MV6) superimposed onto pyruvate carboxylase with phosphonoacetate bound (PDB entry 3TW6). 




Figure 5.

(A) Electron density corresponding to $\mathrm{N1}^{\prime}$-methoxycarbonyl biotin methyl ester and ADP. The displayed electron density is a simulated annealing $\left|F_{\mathrm{O}}-F_{\mathrm{c}}\right|$ map contoured at $3 \sigma$ from which the coordinates for the ligands were omitted. (B) Intermolecular interactions between bicarbonate and biotin carboxylase. Possible hydrogen bonds are indicated by dashed lines. (C) Electron density corresponding to phosphate and ADP. The displayed electron density is a simulated annealing $\left|F_{\mathrm{O}}-F_{\mathrm{c}}\right|$ map contoured at $3 \sigma$ from which the coordinates for the ligands were omitted. 


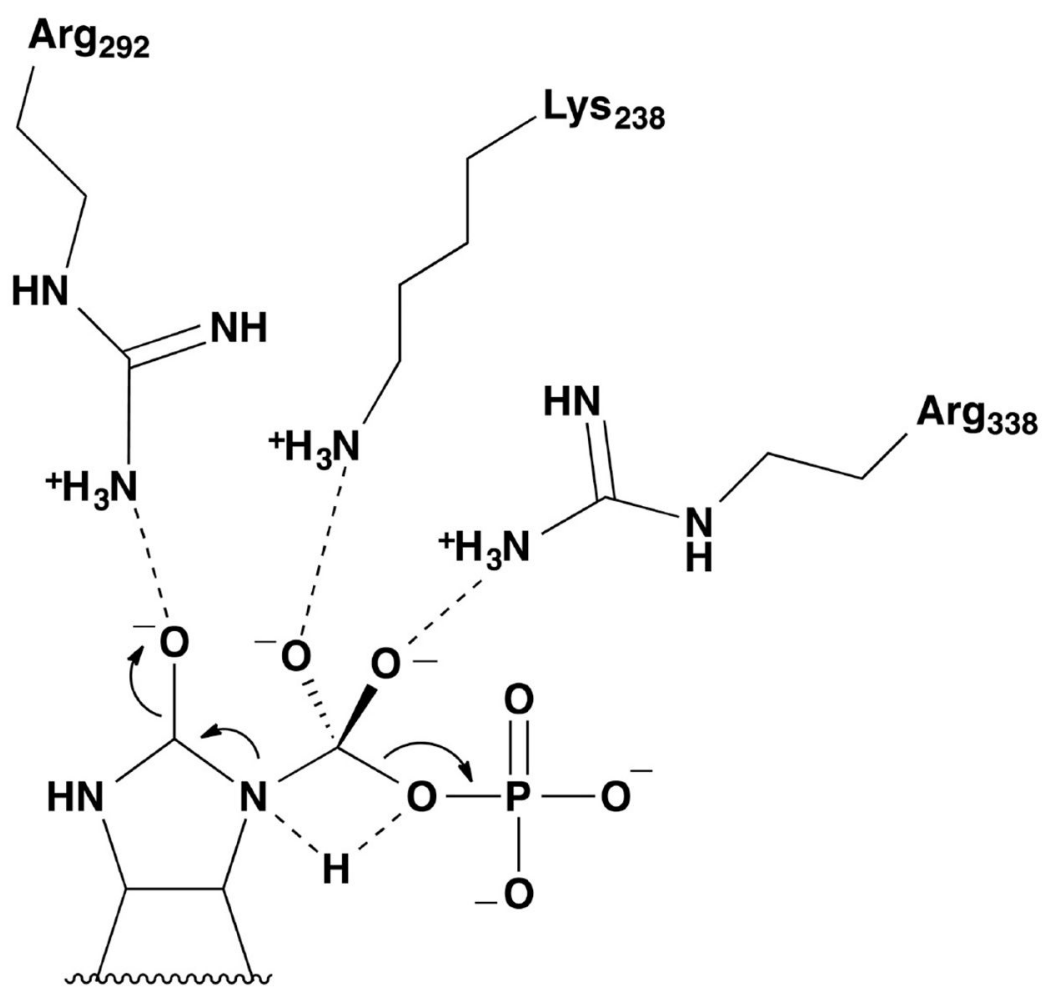

Figure 6.

Schematic of the proposed tetrahedral transition state for the direct transfer of $\mathrm{CO}_{2}$ from the carboxyphosphate intermediate to $\mathrm{N}^{\prime}$ of biotin. 


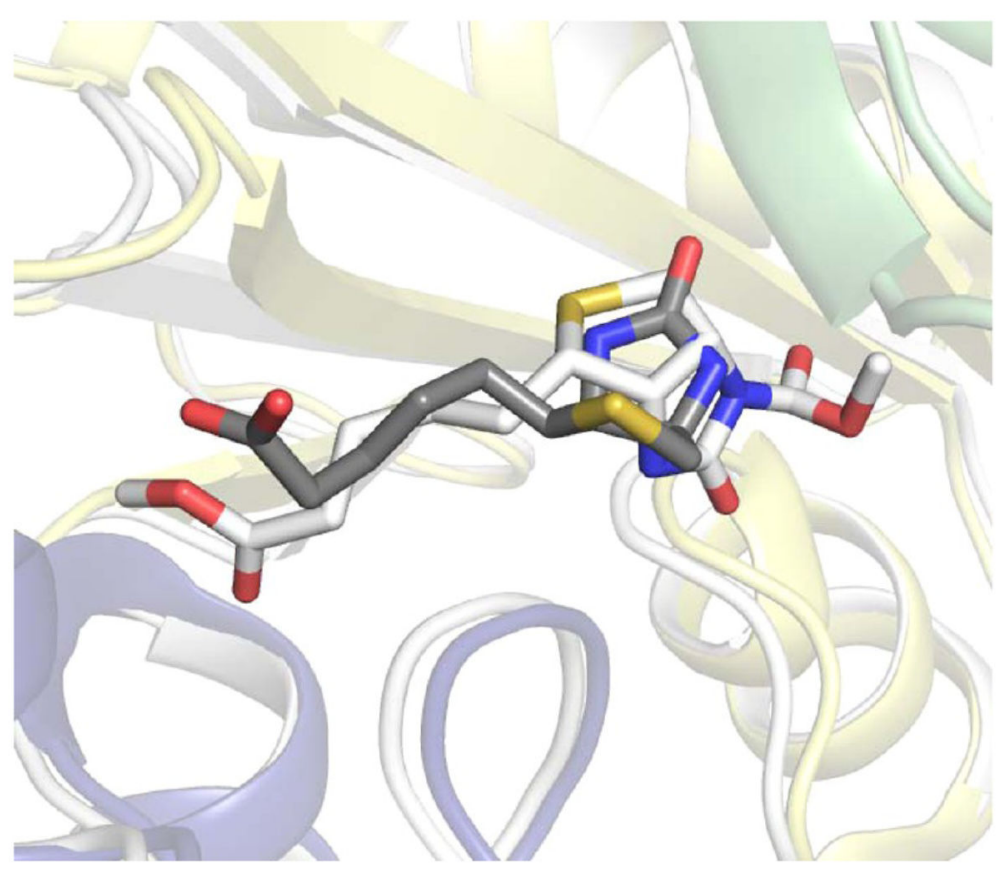

Figure 7.

Biotin carboxylase bound to $\mathrm{N}^{\prime}$-methoxycarbonyl biotin methyl ester (PDB entry 4RZQ) superimposed onto biotin carboxylase with biotin bound (PDB entry 3G8C). 


$$
\begin{array}{clc}
\text { E-biotin }+\mathrm{MgATP}^{-\mathrm{HCO}_{3}{ }^{-}} \stackrel{\mathrm{Mg}^{2+}}{\rightleftharpoons} & \text { E-biotin- } \mathrm{CO}_{2}^{-}+\mathrm{MgADP}+\mathrm{P}_{\mathrm{i}} \\
\text { E-biotin- } \mathrm{CO}_{2}^{-}+\text {acceptor } & \rightleftharpoons & \text { E-biotin + acceptor- } \mathrm{CO}_{2}^{-}
\end{array}
$$

Scheme 1.

Biochemistry. Author manuscript; available in PMC 2016 June 23. 


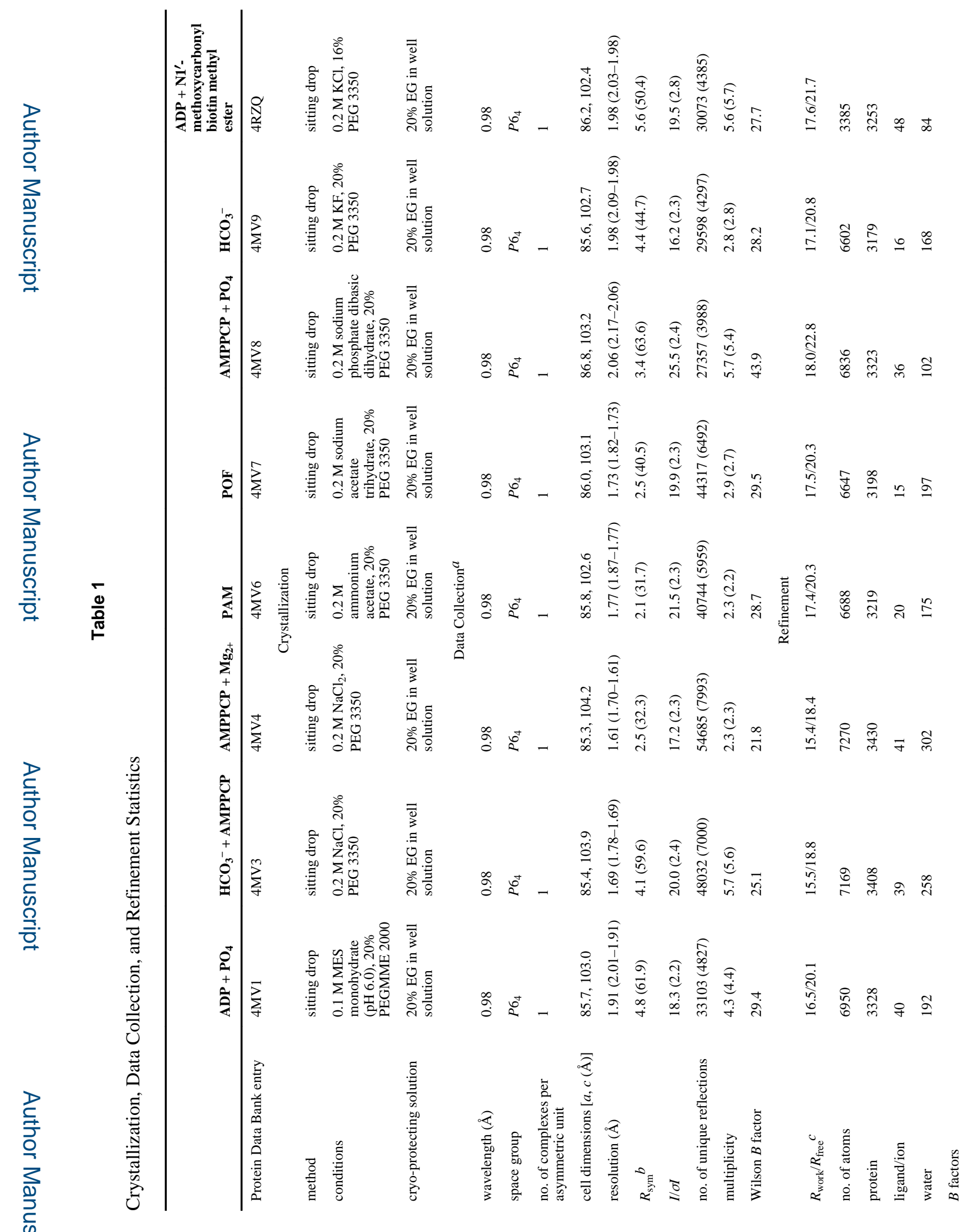

Biochemistry. Author manuscript; available in PMC 2016 June 23. 
Broussard et al.

Page 23

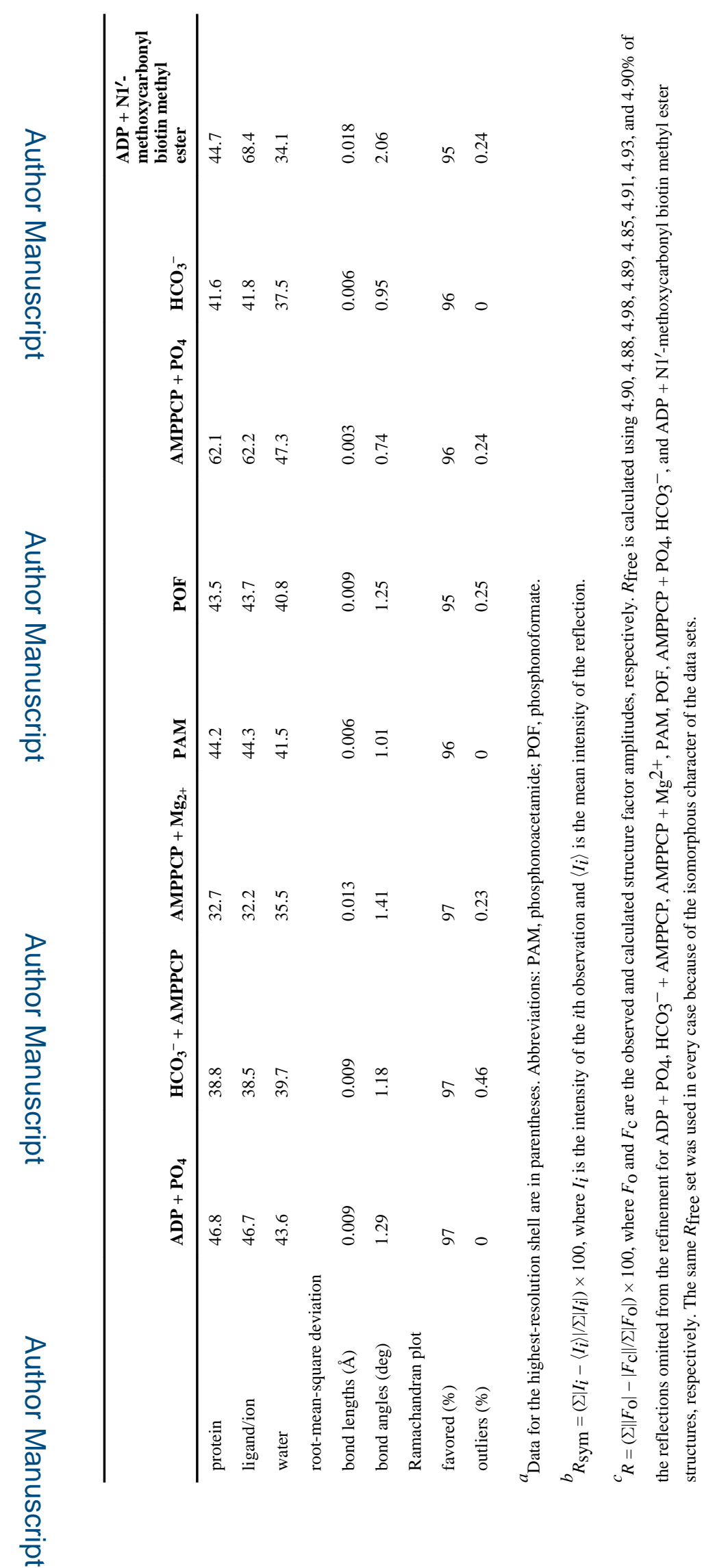

Biochemistry. Author manuscript; available in PMC 2016 June 23. 